\section{Dementia

\title{
Technology and Dementia: The Future is Now
}

\author{
Arlene J. Astell ${ }^{\mathrm{a}-\mathrm{d}}$ Nicole Bouranis ${ }^{\mathrm{e}}$ Jesse Hoey $^{\mathrm{f}} \quad$ Allison Lindauer $^{\mathrm{g}}$ \\ Alex Mihailidis $^{\mathrm{a}}$ Chris Nugent $^{\mathrm{h}}$ Julie M. Robillard ${ }^{\mathrm{i}}$ Technology and \\ Dementia Professional Interest Area ... \\ ${ }^{a}$ Department of Occupational Sciences and Occupational Therapy, University of Toronto, \\ Toronto, ON, Canada; ${ }^{b}$ Department of Psychiatry, University of Toronto, Toronto, ON, \\ Canada; ${ }^{\mathrm{C}}$ Toronto Rehabilitation Institute, Toronto, Toronto, ON, Canada; ${ }^{\mathrm{d}}$ School of \\ Psychology and Clinical Language Sciences, University of Reading, Reading, UK; ${ }^{\text {e Layton }}$ \\ Aging and Alzheimer's Disease Center, Oregon Health and Science University, Portland, \\ $\mathrm{OR}$, USA; f David R. Cheriton School of Computer Science, University of Waterloo, Waterloo, \\ ON, Canada; ${ }^{9}$ Oregon Roybal Center for Aging and Technology (ORCATECH), Oregon \\ Health and Science University, Portland, OR, USA; ${ }^{~}$ School of Computing, Ulster University, \\ Northern Ireland, UK; ${ }^{i}$ Faculty of Medicine, University of British Columbia, Vancouver, BC, \\ Canada
}

\section{Keywords}

Technology $\cdot$ Dementia $\cdot$ Aging $\cdot$ Big data $\cdot$ Policy

\begin{abstract} meaningful and fulfilling life with dementia.

Background: Technology has multiple potential applications to dementia from diagnosis and assessment to care delivery and supporting ageing in place. Objectives: To summarise key areas of technology development in dementia and identify future directions and implications. Method: Members of the US Alzheimer's Association Technology Professional Interest Area involved in delivering the annual pre-conference summarised existing knowledge on current and future technology developments in dementia. Results: The main domains of technology development are as follows: (i) diagnosis, assessment and monitoring, (ii) maintenance of functioning, (iii) leisure and activity, (iv) caregiving and management. Conclusions: The pace of technology development requires urgent policy, funding and practice change, away from a narrow medical approach, to a holistic model that facilitates future risk reduction and prevention strategies, enables earlier detection and supports implementation at scale for a 
Astell et al.: Technology and Dementia

\section{Introduction}

Smartphones and tablets have opened up personal computing to many new audiences and have created increasing interest in how such devices can be used across all aspects of our lives and society. Similarly, wearables, smart home systems (e.g., Amazon Alexa, Google Home Hub), robots, virtual reality (VR), artificial intelligence (AI) and autonomous (i.e., driverless) vehicles are triggering questions about how we can deliver better services, create efficiencies and improve wellbeing, including for those living with dementia. Although research applying technology to dementia has only recently gained mainstream attention, work has been taking place alongside biomedical and health informatics research for many decades. This article produced by members of the Alzheimer's Association Technology Professional Interest Area Executive Committee introduces the main areas of technological focus in dementia and implications for the future. Our views of where technology is going are informed by our direct experience of working with people with dementia with past and present technology.

\section{Diagnosis, Assessment and Monitoring}

The longest-standing use of technology in dementia is in assessment. Two touchscreenbased cognitive assessment batteries - Cambridge Neuropsychological Test Automated Battery [1] and Examen Cognitif par Ordinateur [2] were developed in Europe in the 1980s and 1990s. More recently multiple web-based and app-based cognitive assessments have emerged [3] including digitized versions of pen and paper tasks, such as clock drawing [4] including a digital clock-drawing pen [5]. In addition, the manner in which people use technology and changes in their patterns of use has been identified as an early indicator of emerging cognitive impairment $[6,7]$. Technological assessment of functional activities extends to tasks such as making tea and toast [8], coffee-making [9], as well as instrumental activities of daily living [10].

In terms of dementia diagnosis, there have been increasing applications of various machine learning approaches, most commonly with imaging data for diagnosis and disease progression [11]. This includes amyloid PET imaging [12], MR imaging [13] and combined PET and MR imaging [14]. Non-imaging studies have generally focused on demographic data and cognitive measures [15], although more recent studies have utilized novel linguistic analysis [16] and unobtrusive monitoring of gait patterns over time [17].

The use of big data in dementia research has also recently emerged. The Big Data for Advancing Dementia Research project initiated by the G8 Health Ministers to explore the use of big data in dementia research, concluded that big data could potentially accelerate dementia research and technology development by helping recognize factors that contribute to dementia, identifying individuals with dementia earlier, promoting better support for dementia care and creating new analysis methods (e.g., data mining) that could result in new research opportunities [18]. Examples of data mining in dementia include working with large, pre-existing data registries and health records to investigate co-morbidities with dementia and other diseases [19], combining different data sources including fluid biomarkers and MRI [20] and Alzheimer's disease drug repositioning [21].

\section{Maintenance of Function}

Ongoing monitoring using technology has the potential to both detect progression of dementia over time [22] and to provide prompts and support to individuals to maintain their activities [23]. In 2007, Carrillo et al. [24] identified a gap in knowledge around the delivery of digital prompts, specifically, how best to prompt, what to prompt or when to prompt. A body of work has emerged addressing prompting with Cognitive Assistive Technologies [23]. For example, the Cognitive Orthosis for Assisting aCtivities at Home (COACH) [25] system was created to prompt people with dementia to take them through the hand washing procedures. 
$\mathrm{COACH}$ combines computer vision for tracking the current stage of activity with AI techniques to decide what prompt is required to deliver verbal and visual prompts when people wash their hands. This highly influential work has informed many subsequent systems and led to the notion of "zero effort technologies" [26], which require little or no effort from the people who use them. Zero effort technologies perform the collection, analysis and application of data about the user and/or his/her context using advanced computing techniques, such as computer vision, sensor fusion, decision-making and planning, machine learning and the Internet of things (IoT). Recent work focusses on integrating models of identity and emotion into prompting systems to make them easier to integrate seamlessly into people's lives [27].

Other examples of Cognitive Assistive Technologies combine sensors with AI and machine learning embedded in living environments to create "smart homes," which can detect and analyse health [28] and other events. These first emerged in the late 1990s and have evolved to address the needs of people with dementia, informal (family) caregivers, formal (clinical) caregivers and social (i.e., nonmedical) caregivers [29]. The Gloucester Smart Home [30], an early prototype for individuals with dementia coupled bath and cooker monitors with an automated nightlight, item locator and digital message board to provide visual and verbal prompts such as "time for your medication." More recent examples leverage advances in sensor technology, AI and machine learning to support cooking [31], dressing [32] and reduce demands for caregiving [29]. In addition, smart home technologies are becoming available for individuals to install themselves [33], creating huge potential for conducting scalable clinical trials at home [34, 35].

The availability of cloud computing allows dementia researchers and practitioners to utilize powerful computing resources without the need for specialized computing backgrounds. The result is that research is less expensive and faster to produce results. For these reasons, many novel research projects investigating cloud-based solutions to dementia care, treatment and diagnosis have recently emerged. Examples include supporting aging-in-place and activity monitoring [36], providing location tracking [37], and supporting analysis and interpretation of neuroimaging data [38].

\section{Leisure and Activities}

Supporting social and leisure activities is another area of technological focus in dementia. Musical memory is relatively spared in dementia [39] and multiple technology projects have leveraged this including the one-button radio [40], simple music-making interface [41] and collaborative music making [42]. Enjoying art has also led to programmes such as House of Memories $^{1}$, an interactive art installation for care homes [43], making art as an enjoyable pastime [44] and a more focused art therapy programme [45, 46].

Participating in activities outside the home remains important for persons with dementia. Navigation and route-finding can, however, become challenging and numerous technological solutions have been developed to support these activities [47] and enable "safe walking" [48, 49]. Smart phones with GPS and map functions, offer functionality to support wayfinding [50], including identifying indicators of disorientation to support navigation prompting [51]. For those who have difficulty getting out or participating in regular exercise, virtual cycling [52] and navigating virtual environments [53] can offer enjoyable alternatives.

Socialising is another key activity that people want to do that is important for their wellbeing and maintenance of cognitive function. CIRCA (Computer Interactive Reminiscence and Conversation Aid) [54], a multimedia touchscreen application promotes social interaction which benefits caregiving relationships [55] and improves cognition and quality of life of people with dementia [56]. Socialising through storytelling has been demonstrated with

${ }^{1}$ http://www.liverpoolmuseums.org.uk/learning/documents/house-of-memories-evaluation-report.pdf 
"StoryTable" (de Waag Society) [57], and remote socialising with family and friends using videoconferencing technologies (e.g., Skype, FaceTime) increases positive emotions [58] and reduces agitation [59].

Games and other digital pastimes have also been widely explored [60], with both bespoke, for example, Eldergames [61], Living in the Moment [62] and consumer products (e.g., gaming consoles, tablets) utilised for people with dementia. The potential of digital activities for brain training either to reduce dementia risk has attracted much popular attention. However, while there is consistent evidence of improvement in the aspect of cognitive function that is trained (e.g., processing speed), to date there is no substantial evidence for dementia prevention or delaying decline [63]. However, the FINGER trial has demonstrated that computerised cognitive training can be beneficial in reducing dementia risk as one part of a multidimensional lifestyle intervention [64].

From a leisure and pleasure perspective, mainstream mobile applications can be accessible for people with dementia [65] and motion-based gaming systems (e.g., Nintendo Wii and Xbox Kinect) can provide enjoyable group activities [66]. VR for dementia has also attracted recent attention [67], not just as a leisure activity, but also an assessment tool [68] and for delivering cognitive training [69]. The potential of VR and augmented reality, so-called mixed reality technologies, to support people with dementia in everyday activities, is currently being explored [70].

\section{Caregiving and Management}

Caregiving is another key target of dementia technology. While the potential of robots to complement or even replace human caregivers has attracted much recent attention, research has been underway for many years (e.g., [71, 72]). Recent projects have coupled social presence robots with remote monitoring using sensors and videoconferencing (via tablets) to deliver "virtual visits" [73]. Other robotics-based applications that have been explored for persons with dementia include supporting food preparation [25], eating [74] and participation in recreational activities [75] in care homes.

Supporting informal caregiving (e.g., [76-78]), and delivering care remotely (e.g., [79, 80]) are major challenges that can be addressed at least in part through dementia technology. Across the world, the majority of people with dementia live at home cared for by family members [81]. This caregiving activity represents approximately USD 1 trillion per annum [81] and takes a greater toll on caregiver mental and physical health than caring for other conditions [82]. Unsurprisingly, a large part of caregiver Internet use relates to the demands of caregiving and managing their own health [83]. Despite a large amount of Internet-based interventions being developed and launched for caregivers, there is lack of systematic, largescale studies examining their efficacy [84]. Further, research that unobtrusively assesses caregiver burden is in the early, but promising, stages (Thomas et al., this issue [95]).

In terms of care management, the IoT facilitates the connection between items in the real world and computer systems, providing data more easily, efficiently and economically. IoT in dementia research [85] includes early detection through in-home sensors [86], wearable monitoring [87] and integration of devices for healthcare management [88].

\section{Future Scoping}

Future directions in dementia therapy are predicted to include nanotechnology either to "repair" brain damage [89] or for drug delivery [90]. While there are still many obstacles to resolve, work on nanoparticle and implantable therapeutics to locally deliver chemotherapy for treating brain tumours [91], opens up huge possibilities for delivering new types of interventions for people either with dementia or ideally, before dementia develops. New means of 
data collection, ubiquitous monitoring technologies, population surveillance, data mining and modelling may all play a key role in accelerating the development pipeline of preventive therapeutics for dementia.

\section{Discussion/Conclusion}

Alongside the rapid pace of innovation, policy and practice move much more slowly. To maximise the current and future benefits of technology for dementia, urgent change is needed in services and policies. This includes radically rethinking what people with dementia need in order to live with this condition now and in the future, and how this is going to be provided. Continuing to view dementia as purely a clinical matter addressed with medication and, to a limited extent direct healthcare, is no longer an option as it fails to address the majority of concerns, needs and wishes of people with dementia in their everyday lives. Existing technology can collect prospective data, model risk and provide supportive monitoring. Mainstream devices have the potential to empower people with dementia in many activities and pursuits; however, adoption rates remain low, in part due to lack of awareness or challenges in accessibility (including financial) and support. Harnessing the power of everyday (i.e., off the shelf) technologies raises major questions about funding and finance, not only in insurance-based healthcare systems, but also in publicly funded systems, as many consumer devices (e.g., smart phones) are not classified as medical devices and therefore cannot be "prescribed" by clinicians. While specific software, such as cognitive assessments could be so classified, the use of standard functions of a smart device for maintaining social interaction (through calls, texts, videoconferencing) or cognitive stimulation (through playing games) may not be classified as a medical intervention.

Expanding our view of dementia beyond healthcare can be understood as akin to physical and intellectual disabilities that influence all aspects of a person's life. Taking this view as a starting point, policies are needed that provide people with dementia and their caregivers access to devices, services and other tools to live as well as possible with their condition. This includes creating direct funding streams for technology, providing maintenance and updating support services, delivering new types of digitally enabled services with tech-savvy staff for people with dementia, harnessing big data to predict patterns of need and proactively identify people at risk, and supporting rapid development, testing and deployment of next-generation technological interventions. Supporting the technology-enabled provision of preventive and care interventions also requires a number of ethical issues to be addressed, including privacy, data ownership, sharing and usage, risk, rights, responsibilities and relationships (including data sharing) between private corporations and statutory bodies [92, 93].

With the current research and commercial technology, we have the tools to tackle many of the perceived problems currently associated with dementia. First, technology can be used to target lifestyle factors that are associated with the risk of developing dementia [94]. For those who are diagnosed with dementia, providing them with technology (e.g., apps, wearables, smart home systems), from the point of diagnosis we can monitor the progression of their condition, identify problems emerging, deliver interventions and avoid unnecessary emergency admissions and hospital stays. Such technology can also provide prompts and reminders both within and outside the home to support maintenance of cognitive, social and physical functioning as well as continued completion of daily activities. Technology can also contribute both directly and indirectly to caregiving, reducing demands on families and formal services, which are major contributors to the economic costs of dementia. 


\section{Statement of Ethics}

The authors have no ethical conflicts to disclose.

\section{Disclosure Statement}

The authors declare that they have no conflicts of interest to disclose.

\section{Author Contributions}

A.J.A. drafted the article, N.B., J.H., A.L., C.N., A.M., and J.M.R. all contributed to the development of the concepts and revised the manuscript.

\section{References}

1 Robbins TW, James M, Owen AM, Sahakian BJ, McInnes L, Rabbitt P. Cambridge Neuropsychological Test Automated Battery (CANTAB): a factor analytic study of a large sample of normal elderly volunteers. Dementia. 1994 Sep-Oct;5(5):266-81.

2 Ritchie KA, Huppert FA, Nargeot C, Pinek B, Ledesert B. Computerized cognitive examination of the elderly (ECO): the development of a neuropsychological examination for clinic and population use. Int J Geriatr Psychiatry. 1993;8(11):899-914.

3 Chinner A, Blane J, Lancaster C, Hinds C, Koychev I. Digital technologies for the assessment of cognition: a clinical review. Evid Based Ment Health. 2018 May;21(2):67-71.

4 Cohen J, Penney DL, Davis R, Libon DJ, Swenson RA, Ajilore O, et al. Digital Clock Drawing: differentiating "thinking" versus "doing" in younger and older adults with depression. J Int Neuropsychol Soc. 2014 Oct; 20(9):920-8.

5 Souillard-Mandar W, Davis R, Rudin C, Au R, Libon DJ, Swenson R, et al. Learning Classification Models of Cognitive Conditions from Subtle Behaviors in the Digital Clock Drawing Test. Mach Learn. 2016 Mar;102(3): 393-441.

6 Jimison H, Pavel M, McKanna J, Pavel J. Unobtrusive monitoring of computer interactions to detect cognitive status in elders. IEEE Trans Inf Technol Biomed. 2004 Sep;8(3):248-52.

7 Kaye J, Mattek N, Dodge HH, Campbell I, Hayes T, Austin D, et al. Unobtrusive measurement of daily computer use to detect mild cognitive impairment. Alzheimers Dement. 2014 Jan;10(1):10-7.

8 Wherton JP, Monk AF. Problems people with dementia have with kitchen tasks: the challenge for pervasive computing. Interact Comput. 2010;22(4):253-66.

9 Allain P, Foloppe DA, Besnard J, Yamaguchi T, Etcharry-Bouyx F, Le Gall D, et al. Detecting everyday action deficits in Alzheimer's disease using a nonimmersive virtual reality kitchen. J Int Neuropsychol Soc. 2014 May; 20(5):468-77.

10 König A, Crispim-Junior CF, Covella AG, Bremond F, Derreumaux A, Bensadoun G, et al. Ecological Assessment of Autonomy in Instrumental Activities of Daily Living in Dementia Patients by the Means of an Automatic Video Monitoring System. Front Aging Neurosci. 2015 Jun;7:98.

11 Dallora AL, Eivazzadeh S, Mendes E, Berglund J, Anderberg P. Machine learning and microsimulation techniques on the prognosis of dementia: A systematic literature review. PLoS One. 2017 Jun;12(6):e0179804.

12 Mathotaarachchi S, Pascoal TA, Shin M, Benedet AL, Kang MS, Beaudry T, et al.; Alzheimer's Disease Neuroimaging Initiative. Identifying incipient dementia individuals using machine learning and amyloid imaging. Neurobiol Aging. 2017 Nov; 59:80-90.

13 Cheng B, Liu M, Zhang D, Munsell BC, Shen D. Domain transfer learning for MCI conversion prediction. IEEE Trans Biomed Eng. 2015 Jul;62(7):1805-17.

14 Liu S, Liu S, Cai W, Che H, Pujol S, Kikinis R, et al.; ADNI. Multimodal neuroimaging feature learning for multiclass diagnosis of Alzheimer's disease. IEEE Trans Biomed Eng. 2015 Apr;62(4):1132-40.

15 Bhagyashree SI, Nagaraj K, Prince M, Fall CH, Krishna M. Diagnosis of Dementia by Machine learning methods in Epidemiological studies: a pilot exploratory study from south India. Soc Psychiatry Psychiatr Epidemiol. 2018 Jan;53(1):77-86.

16 Korcovelos EA FK, Meltzer J, Hirst G, Rudzicz F. Studying neurodegeneration with automated linguistic analysis of speech data. Alzheimer's and Dementia 2017;13:Suppl, P164-P165.

17 Dodge HH, Mattek NC, Austin D, Hayes TL, Kaye JA. In-home walking speeds and variability trajectories associated with mild cognitive impairment. Neurology. 2012 Jun;78(24):1946-52. 
Astell et al.: Technology and Dementia

18 Deetjen UM, Schroeder R. Big Data for Advancing Dementia Research : An evaluation of data sharing practices in research. OECD Digit Econ Pap; 2015.

19 Chen PH, Lee DD, Yang MH. Data mining the comorbid associations between dementia and various kinds of illnesses using a medicine database. Comput Electr Eng. 2018;70:12-20.

20 Alipour AP, Khademi M. Alzheimer's disease detection using data mining techniques, MRI imaging, Bloodbased biomarkeres and neuropsychological tests. Res J Recent Sci. 2015;4:1-5.

21 Zhang M, Schmitt-Ulms G, Sato C, Xi Z, Zhang Y, Zhou Y, et al. Drug repositioning for Alzheimer's disease based on systematic "omics" data mining. PLoS One. 2016 Dec;11(12):e0168812.

22 Kaye JA, Maxwell SA, Mattek N, Hayes TL, Dodge H, Pavel M, et al. Intelligent Systems For Assessing Aging Changes: home-based, unobtrusive, and continuous assessment of aging. J Gerontol B Psychol Sci Soc Sci. 2011 Jul;66 Suppl 1:i180-90.

23 Mihailidis A, Boger JN, Craig T, Hoey J. The COACH prompting system to assist older adults with dementia through handwashing: an efficacy study. BMC Geriatr. 2008 Nov;8(1):28.

24 Carrillo MC, Dishman E, Plowman T. Everyday technologies for Alzheimer's disease care: research findings, directions, and challenges. Alzheimers Dement. 2009 Nov;5(6):479-88.

25 Begum M, Wang R, Huq R, Mihailidis A. Performance of daily activities by older adults with dementia: the role of an assistive robot. IEEE Int Conf Rehabil Robot. 2013 Jun;2013:6650405.

26 Boger J, Young V, Hoey J, Jiancaro T, Mihailidis A. Zero-effort technologies: Considerations, Challenges, and Use in Health, Wellness and Rehabilitation. Williston (VT): Morgan \& Claypool; 2018.

27 Robillard JM, Hoey J. Emotion and Motivation in Cognitive Assistive Technologies for Dementia. Computer. 2018;51(3):24-34.

28 Sprint GC, Fritz R, Schmitter-Edgecombe M. Using Smart Homes to Detect and Analyze Health Events. Computer. 2016;49(11):29-37.

29 Amiribesheli MB. A Tailored Smart Home for Dementia Care. J Ambient Intell Humaniz Comput. 2017.

30 Orpwood R GC, Adlam T, Faulkner R, Meegahawatte D. The Gloucester Smart House for People with Dementia - User-Interface Aspects. 2004,

31 Pigot HM, Giroux S. The intelligent habitat and everyday life activity support: 5 th Int Conf Simulations. Biomed Slov April 2003 [Internet] 2003;2-4,

32 Burleson W, Lozano C, Ravishankar V, Lee J, Mahoney D. An assistive technology system that provides personalized dressing support for people living with dementia: capability study. JMIR Med Inform. 2018 May;6(2):e21.

33 Hu Y, Tilke D, Adams T, Crandall AS, Cook DJ, Schmitter-Edgecombe M. Smart home in a box: usability study for a large scale self-installation of smart home technologies. J Reliab Intell Environ. 2016 Jul;2(2):93-106.

34 Kaye J. Home-based technologies: a new paradigm for conducting dementia prevention trials. Alzheimers Dement. 2008 Jan;4(1 Suppl 1):S60-6.

35 Teipel S, König A, Hoey J, Kaye J, Krüger F, Robillard JM, et al. Use of nonintrusive sensor-based information and communication technology for real-world evidence for clinical trials in dementia. Alzheimers Dement. 2018 Sep;14(9):1216-31.

36 Li DP, Piao M, Ryu KH, editors. The design and partial implementation of the dementia-aid monitoring system based on sensor network and cloud computing platform. Volume 619. Springer Cham; 2016.

37 Lin Y, Chen H, Su M. Eighth International Conference on Mobile Computing and Ubiquitous Networking (ICMU). Hakodate, Japan, 2015

38 Shen LK, Preuss N. The three nitrcs: Software, data and cloud computing for brain science and dementia research. Alzheimers Dement. 2013;94 supp:78.

39 Jacobsen JH, Stelzer J, Fritz TH, Chételat G, La Joie R, Turner R. Why musical memory can be preserved in advanced Alzheimer's disease. Brain. 2015 Aug;138(Pt 8):2438-50.

40 Orpwood RC, Howcroft D, Sixsmith A, Torrington J, Gibson G, et al. Designing technology to improve quality of life for people with dementia: user-led approaches. Univers Access Inf Soc. 2010;9(3):249-59.

41 Riley P, Alm N, Newell A. An interactive tool to promote musical creativity in people with dementia. Comput Human Behav. 2009;25(3):599-608.

42 Favela S, Pedell S. Touch screen ensemble music: Collaborative interaction for older people with dementia. 25th Australian Computer-Human Interaction Conference: Augmentation, Application, Innovation, Collaboration. Adelaide, Australia, ACM, New York; 2013, pp 481-484.

43 Luyten T, Braun S, Jamin G, van Hooren S, de Witte L. How nursing home residents with dementia respond to the interactive art installation 'VENSTER': a pilot study. Disabil Rehabil Assist Technol. 2018 Jan;13(1):87-94.

44 Lazar AC, Edasis C, Piper AM. Designing for the Third Hand : Empowering Older Adults with Cognitive Impairments through Creating and Sharing.: 2016 ACM Conference on Designing Interactive Systems. Brisbane, Australia, ACM, New York, NY, 2016, pp 1047.

45 Mihailidis AB, Boger J, Richards B, Zutis K, Young L, et al. Towards the development of a technology for art therapy and dementia: definition of needs and design constraints. Arts Psychother. 2010;37(4):293-300.

46 Leuty V, Boger J, Young L, Hoey J, Mihailidis A. Engaging older adults with dementia in creative occupations using artificially intelligent assistive technology. Assist Technol. 2013;25(2):72-9.

47 Liao LP, Fox D, Kautz H. Learning and inferring transportation routines. Artif Intell. 2007;171:311-331.

48 Wood EW, Woolham J. The development of safer walking technology: A review. J Assist Technol. 2015;9(2): 100-15. 
49 Teipel S, Babiloni C, Hoey J, Kaye J, Kirste T, Burmeister OK. Information and communication technology solutions for outdoor navigation in dementia. Alzheimers Dement. 2016 Jun;12(6):695-707.

50 Kwan RYC, Cheung DSK, kor PP-K, The use of smartphones for wayfinding by people with dementia. Dementia 2018.

51 Koldrack P, Teipel S, Kirste T. Sensing disorientation of persons with dementia in outdoor wayfinding tasks using wearable sensors to enable situation-aware navigation assistance. Alzheimer's \& Dementia 2016; 12(suppl):160.

52 Schikhof YW. Two types of stimuli in virtual cycling for people with dementia. Gerontechnology (Valkenswaard). 2016;15 Suppl:163S.

53 Blackman T, Van Schaik P, Martyr A. VSP, Martyr A.: Outdoor environments for people with dementia : an exploratory study using virtual reality. Ageing Soc. 2007;27(06):811-25.

54 Alm NA, Ellis M, Dye R, Gowans G, Campbell J. A cognitive prosthesis and communication support for people with dementia [Internet]. Neuropsychol Rehabil. 2004;14(1-2):117-34.

55 Astell AJ, Bernardi L, Alm N, Dye R, Gowans G, et al. Using a touch screen computer to support relationships between people with dementia and caregivers. Interact Comput. 2010;22(4):267-75.

56 Astell AJ, Smith SK, Potter S, Preston-Jones E. Computer Interactive Reminiscence and Conversation Aid groups-Delivering cognitive stimulation with technology. Alzheimers Dement (N Y). 2018 Sep;4:481-7.

57 Knipscheer K, Nieuwesteeg J, Oste J. Persuasive Story Table: Promoting Exchange of Life History Stories Among Elderly in Institutions. Int Conf Persuas Tehcnology; 2006. pp 191-194.

58 Hori M, Kubota M, Ando K, Kihara T, Takahashi R, Kinoshita A. The effect of videophone communication (with skype and webcam)for elderly patients with dementia and their caregivers. Gan To Kagaku Ryoho. 2009 Dec; 36 Suppl 1:36-8.

59 Van der Ploeg ES, Eppingstall B, O'Connor DW. Internet video chat (Skype) family conversations as a treatment of agitation in nursing home residents with dementia. Int Psychogeriatr. 2016 Apr;28(4):697-8.

60 McCallum SB. Dementia games: A literature review of dementia-related serious games., ed Lecture Notes in Computer Science (including subseries Lecture Notes in Artificial Intelligence and Lecture Notes in Bioinformatics). 2013.

61 Gamberini LM, Seraglia B, Spagnolli A, Fabregat M, Ibanez F, et al. Eldergames project: An innovative mixed reality table-top solution to preserve cognitive functions in elderly people. Proceedings - 2009 2nd Conference on Human System Interactions, HSI '09; 2009.

62 Astell AA, Dye R, Gowans G, Vaughan P, Ellis M. Digital video games for older adults with cognitive impairment. Lecture Notes in Computer Science (including subseries Lecture Notes in Artificial Intelligence and Lecture Notes in Bioinformatics) 2014;8547.

63 Butler M, McCreedy E, Nelson VA, Desai P, Ratner E, Fink HA, et al. Does Cognitive Training Prevent Cognitive Decline?: A Systematic Review. Ann Intern Med. 2018 Jan;168(1):63-8.

64 Ngandu T, Lehtisalo J, Solomon A, Levälahti E, Ahtiluoto S, Antikainen R, et al. A 2 year multidomain intervention of diet, exercise, cognitive training, and vascular risk monitoring versus control to prevent cognitive decline in at-risk elderly people (FINGER): a randomised controlled trial. Lancet. 2015 Jun;385(9984):225563.

65 Joddrell PH, Astell AJ. Identifying existing, accessible touchscreen games for people living with dementia. Lect Notes Comput Sci. 2016;9758:509-14.

66 Dove E, Astell A. The Kinect Project: group motion-based gaming for people living with dementia. Dementia. 2017 Jan 1:1471301217743575.

67 Garcia-Betances RI, Fico G, Cabrera-Umpierrez MF, editors. A succinct overview of virtual reality technology use in Alzheimer's disease. [Internet]. Universidad Politecnica de Madrid, Politecnica de Madrid, Av. Complutense s/n, Madrid, Spain, 28040, rgarcia@lst.tfo.upm.es: Frontiers Media S.A.; 2015, Life Supporting Technologies (LifeSTech), ETSI Telecomunicaciones; 2015.

68 Seo K, Kim JK, Oh DH, Ryu H, Choi H. Virtual daily living test to screen for mild cognitive impairment using kinematic movement analysis. PLoS One. 2017 Jul;12(7):e0181883.

69 García-Betances RI, Jiménez-Mixco V, Arredondo MT, Cabrera-Umpiérrez MF. Using virtual reality for cognitive training of the elderly. Am J Alzheimers Dis Other Demen. 2015 Feb;30(1):49-54.

70 Hayhurst J, editor. How augmented reality and virtual reality is being used to support people living with dementia: Design challenges and future directions. 2018.

71 Roy N BG, Fox D, Gemperle F, Goetz J, Hirsch T, et al. Towards Personal Service Robots for the Elderly. Work Interact Robot Entertain (WIRE 2000). 25:184.

72 Pineau JM, Pollack M, Roy N, Thrun S, editors. Towards robotic assistants in nursing homes: Challenges and results.

73 Coradeschi SC, Cortellessa G, Coraci L, Gonzalez J, Karlsson L, et al. GiraffPlus: Combining social interaction and long term monitoring for promoting independent living. 6th International Conference on Human System Interactions; 2013. pp 578-585.

74 Derek MC, Nejat G. A Socially Assistive Robot for Meal-Time Cognitive Interventions [Internet]. J Med Device. 2012;6(1):6.

75 Louie WY, Mohamed C, Despond F, Lee V, Nejat G. Tangy the Robot Bingo Facilitator: A Performance Review [Internet]. J Med Device. 2015;9. 
Astell et al.: Technology and Dementia

76 Chiu T, Marziali E, Colantonio A, Carswell A, Gruneir M, Tang M, et al. Internet-based caregiver support for Chinese Canadians taking care of a family member with alzheimer disease and related dementia. Can J Aging. 2009 Dec;28(4):323-36.

77 Czaja SJ, Loewenstein D, Schulz R, Nair SN, Perdomo D. A videophone psychosocial intervention for dementia caregivers. Am J Geriatr Psychiatry. 2013 Nov;21(11):1071-81.

78 Williams K, Arthur A, Niedens M, Moushey L, Hutfles L. In-home monitoring support for dementia caregivers: a feasibility study. Clin Nurs Res. 2013 May;22(2):139-50.

79 Lee JH, Kim JH, Jhoo JH, Lee KU, Kim KW, Lee DY, et al. A telemedicine system as a care modality for dementia patients in Korea. Alzheimer Dis Assoc Disord. 2000 Apr-Jun;14(2):94-101.

80 Wang LY, Robinson MN, Fredrickson KR, Thielke SM, Tsuang DW, et al. A Dementia Care Shared Medical Visit Model for Patients and Caregivers Using Telemedicine. J Neuropsychiatry Clin Neurosci. 2014.

81 Prince MW, Guerchet M, Gemma-Claire A, Wu YT, Prina M. World Alzheimer Report 2015: The Global Impact of Dementia - An analysis of prevalence, incidence, cost and trends. Alzheimer's Dis Int; 2015. p. 84.

82 Ory MG, Hoffman RR 3rd, Yee JL, Tennstedt S, Schulz R. Prevalence and impact of caregiving: a detailed comparison between dementia and nondementia caregivers. Gerontologist. 1999 Apr;39(2):177-85.

83 Kim H. Understanding Internet Use Among Dementia Caregivers: Results of Secondary Data Analysis Using the US Caregiver Survey Data. Interact J Med Res. 2015 Feb;4(1):e1.

84 Boots LM, de Vugt ME, van Knippenberg RJ, Kempen GI, Verhey FR. A systematic review of Internet-based supportive interventions for caregivers of patients with dementia. Int J Geriatr Psychiatry. 2014 Apr;29(4): 331-44.

85 Dimirioglou N, Kardaras D, Barbounaki S. Multicriteria Evaluation of the Internet of Things Potential in Health Care: The Case of Dementia Care. IEEE 19th Conference on Business Informatics; 2017.

86 Ishii H, Kimino K, Aljehani M, Ohe N, Inoue M. An Early Detection System for Dementia Using the M2 M/IoT Platform. Procedia Comput Sci. 2016;96:1332-40.

87 Shin DS, Shin D, Shin D. Ubiquitous health management system with watch-type monitoring device for dementia patients. J Appl Math. 2014;2014:1-8.

88 Enshaeifar S, Zoha A, Markides A, Skillman S, Acton ST, Elsaleh T, et al. Health management and pattern analysis of daily living activities of people with dementia using in-home sensors and machine learning techniques. PLoS One. 2018 May;13(5):e0195605.

89 Saniotis A, Henneberg M, Sawalma AR. Integration of Nanobots Into Neural Circuits As a Future Therapy for Treating Neurodegenerative Disorders. Front Neurosci. 2018 Mar;12:153.

90 Li X, Tsibouklis J, Weng T, Zhang B, Yin G, Feng G, et al. Nano carriers for drug transport across the blood-brain barrier. J Drug Target. 2017 Jan;25(1):17-28.

91 Chakroun RW, Zhang P, Lin R, Schiapparelli P, Quinones-Hinojosa A, Cui H. Nanotherapeutic systems for local treatment of brain tumors. Wiley Interdiscip Rev Nanomed Nanobiotechnol. 2018 Jan;10(1):10.

92 Robillard JM, Illes J, Arcand M, Beattie BL, Hayden S, Lawrence P, et al. Scientific and ethical features of Englishlanguage online tests for Alzheimer's disease. Alzheimers Dement (Amst). 2015 Jul;1(3):281-8.

93 Robillard JM, Cleland I, Hoey J, Nugent C. Ethical adoption: A new imperative in the development of technology for dementia. Alzheimers Dement. 2018 Sep;14(9):1104-13.

94 Hartin PJ, Nugent CD, McClean SI, Cleland I, Tschanz JT, Clark CJ, et al. JoAnn T. Tschanz, Christine J. Clark, and Maria C. Norton. The empowering role of mobile apps in behavior change interventions: the Gray Matters randomized controlled trial. JMIR Mhealth Uhealth. 2016 Aug;4(3):e93.

95 Thomas NWD, Lindauer A, Kaye J. EVALUATE-AD and Tele-STAR: novel methodologies for assessment of caregiver burden in a telehealth caregiver intervention - a case study. Dement Geriatr Cogn Disord. 2019; 47:175-83. 